\title{
Analyzing The Problem And Prospects Of Ecotourism: A Review On Bangladesh
}

\author{
NushratNahida Afroz ${ }^{1}$; Md. Shahed Mahmud ${ }^{2}$. \\ ${ }^{1,2,}$ Department of Business Administration, MawlanaBhashani Science and Technology University, Santosh, \\ Tangail-1902.
}

\begin{abstract}
Tourism especially ecotourism is one of the most promising sectors for Bangladesh with her huge natural beauty, heroic historical background and archaeological resources. The purpose of this study is to find out the problem and prospects of ecotourism in Bangladesh. According to World Travel and Tourism Council (WTTC), by the year of 2025 tourism sector will contribute nearly 4.4\% (BDT 1,252.8 billion) of the total GDP of Bangladesh. This study reveals the current status of ecotourism in Bangladesh and find out the snags and visions for ecotourism in Bangladesh. Secondary data sources used to conduct the research. This study found, there is no comprehensive ecotourism plan exists in Bangladesh right now. Some recommendations are made for the development of ecotourism in Bangladesh to be one of the popular tourist destination worldwide. For that, the government along with the private sector should come forward and formulate a clear long term vision to develop the ecotourism in Bangladesh.
\end{abstract}

Keyword: Ecotourism, Problem and prospects, Bangladesh.

\section{Introduction}

Over the last couple of decades, the tourism sector has gone through an incredible growth and a hand full of divergence made one of the fastest growing sectors in the world (UNWTO). According to World Tourism Organization (UNWTO, 2016), international tourism has grown significantly than the world trade in the last couple of years. Probably, there exists a very few sectors in the world, which touches so many sectors as tourism does (Cater, 1995). Thus, tourism as a single industry contributes a lot to the economy of country and region as well.

Basically, Tourism refers to travel for recreation, leisure, medical or business purposes from one place to another place for maximum one year or less time period. As World Tourism Organization (WTO) defines tourism as, "Tourism comprises the activities of persons traveling to and staying in places outside their usual environment for not more than one consecutive year for leisure, business and other purposes" (Ugurlu, 2010). As the rise of the tourism increasing in the last couple of decades, the call for socially and environmentally responsible tourism came to the limelight. The term 'ecotourism' came to the limelight over the last three decades as an alternative to mass tourism (Russell \& Wallace, 2004). Sensible tourism to natural areas, that protects the environment and develops the wellbeing of local people defined as ecotourism(Das, 2011). Moreover, ecotourism also caught the attention of diverse benefits, both as profitable leisure activity, and as a means of protection and improvement of the natural environment (Das, 2011).

Countries like Bangladesh has a huge potential in the sector of ecotourism. According to the statistics of 2014, travel and tourism has a total contribution of $4.1 \%$ of the GDP of Bangladesh and predicted to be increased by $06 \%$ within the year 2025 ((WTTC), 2015). Bangladesh is the land of beauty. Historical places, monuments, natural sites, beaches, tribal people, resorts, forests, wildlife of various species are the major tourism destination of Bangladeshi (Wikipedia, 2017b). Formulating and proper implementation of long term strategic plan and positive attitude towards the Bangladeshi attractive sites can easily foster the growth of ecotourism of Bangladesh. The government along with the private sectors may come forward and contribute to create the pile of the ecotourism. As a result, this will create an employment generation in the country and add value in the gross domestic product. Furthermore, this will have a positive impact on raising gross domestic product through improving variables of the macro economy of the country.

\section{Objective}

The main objective of this study is to concentrate on the issues relevant to the problem and potentiality of tourism industry in Bangladesh. However, the specific objectives of this study are:

i. To know the current scenario of the ecotourism in Bangladesh;

ii. To know the existing problems associated with the ecotourism development in Bangladesh;

iii. Prescribe some suggestions for reforms and improvements of the ecotourism in Bangladesh. 


\section{Literature Review}

Shamsuddoha and Nasir (2011)did a study on Sitakundaeco-park in Chittagong division of Bangladesh. In that research they explored the opportunities of ecotourism in sub-urban city. According to the researchers, to maintain the natural balance Bangladesh is trying to develop a number of eco-parks and by this time there exists half a dozen of eco-park in Bangladesh. But in most of the cases, the eco-park does not have a minimum standard as the lack of infrastructure and other problems slow the pace of developing a model good ecotourism culture.

Rasul and Manandhar (2009) conducted a study to investigate the problems and the prospects of promoting tourism in South Asian region. In that study, they were able to portray that, despite huge potentials the tourism sector is struggling till date. A number of factors, such as complex travel procedure, safety and security, negative image, poor facilities and services constitute the problems. The study also reveals that, strong political commitment and less bureaucratic legislation can remove the major barriers for booming the tourism sector in South Asian region.

Okaka (2007) tried to find out the role of media communications in formulating tourism strategy and cross cultural communication for peace, safety for sustainable tourism industry in Africa. The researcher pointed out that, the media can play a vital role in the development of sustainable tourism in the African region. Research, interchange of tourism experts and information within the existing economic and regional blocks, joint product or service development, development of human capital and management can be possible with the help of media communication.

Das (2011) lead a study on Ecotourism, Sustainable Development and the Indian State. The main focus of this study was to critically analyze of some of the ecotourism policies and programs of the Indian government. Sustainable development was the basis for evaluating the ecotourism in the study. The researcher showed in this study that, the fragmented nature of ecotourism policies and practices has a contradiction with sustainable tourism, though it plays one of the vital role for ensuring a sustainable development in India. Finally, the study recommended that amendments in procedures, without a thoughtful evaluation, might not successfully accomplish all the gaps involved.

Shoeb-Ur-Rahman and Shahid (2012) conducted a research on the growing dilemma of tourism specially ecotourism and sustainable development in the context of Bangladesh. The researchers tried to provide an impression of how ecotourism destination appeared as a core elements of sustainable development of Bangladesh. Furthermore, to become a major ecotourism destination, they have recommended and pointed out some of the marketing strategies for developing the sector.

Jamrozy (2007) directed a study titled, "Marketing of tourism: a paradigm shift toward sustainability." The purpose of the study was to recommend an alteration in the tourism marketing pattern away from economic profit urgencies towards sustainability. The sustainability method take on a holistic and integrated sight of marketing allowing social equity, ecological safety, and economic liability into consideration. Finally, the study considered a triple bottom line approach, as sustainable tourism marketing adopts an integrated view on tourism marketing.

Salam, Lindsay, and Beveridge (2000) conducted a study on UN's world heritage site, Sundarban of Bangladesh. In their study they tried to describe how the ecotourism protect the Sundarban and maintain a healthy natural environment for the wildlife. The study suggested that, nature oriented tourism can play a vital role to achieve the sustainability in the reserve forests and protecting the world heritage sites as well. The major findings of the study portrait that, the native community, economy of a country and finally the regional economic condition can play a vital role for tourism development. Moreover planned tourism development and a strong political commitment can also boost the growth of tourism development.

Based on the above analysis of literature no works have been found, which analyze directly on problem and prospects of ecotourism in Bangladeshi context. Therefore, an initiative has been taken to address the issue. Furthermore, contribute some suggestions for the concerned authority of tourism industry in Bangladesh for developing a sustainable ecotourism destination.

\section{Methodology}

The study is based on the information from secondary data sources. The secondary data were collected from published books, different published research works, newspaper, magazines, reports of various government and non-government authorities, websites, and official statistical documents. Data recorded by all concerned authorities like Bangladesh Parjatan Corporation, Bangladesh Economic Review and reports from World Tourism and Traveling Council etc. are used for this study. All the data obtained from secondary sources are considered for draw a conclusion. Furthermore, some suggestions are prescribed for the betterment of ecotourism in Bangladesh, so that the economy can take absolute advantage from them. 


\section{Eco-Tourism}

The concept of ecotourism is much related to some other concepts of tourism like, wildlife tourism or adventure tourism. Different researchers describe the ecotourism as one of the extended versions of mass tourism. Some researcher try to demonstrate the term ecotourism as responsible tourism (Russell \& Wallace, 2004). The term ecotourism came to the limelight over the last three decades as an alternative to mass tourism and as a meaning to address the untouched tourism considering the less favorable ecological and social consequences (Russell \& Wallace, 2004). During the period of globalization, both the developed and the developing world facing the challenges of protecting the natural resource worldwide. But the demand for travelling and tourism, especially in the natural areas is increasing day by day. In recent decades, tourism sector has become a multimillion dollar industry, as people are more interested to spend their leisure time in different attractive places around the world ((WTTC), 2015). In the recent decades, ecotourism emerged as one of the most economic, effective and environmentally friendly way of utilizing natural resources and maintain sustainable development in natural reserves (Li \& Han, 2001).

Das (2011) describe ecotourism as, "ecotourism, defined as responsible travel to natural areas, that conserves the environment and improves the welfare of local people, has caught the attention of diverse interests, both as an economically profitable leisure activity, and as a means of conservation and development". Goodwin (1996, p. 288) defined ecotourism as, "low impact nature tourism, which contributes to the maintenance of species and habitats either directly through a contribution to conservation and/or indirectly by providing revenue to the local community sufficient for local people to value, and therefore protect, their wildlife heritage area as a source of income". Wikipedia (2017a) defines ecotourism as, "Ecotourism is a form of tourism involving visiting fragile, pristine, and relatively undisturbed natural areas, intended as a low-impact and often small scale alternative to standard commercial (mass) tourism. It means responsible travel to natural areas, conserving the environment and improving the wellbeing of the local people". Again UNWTO defines some characteristics of ecotourism. According to UNWTO ecotourism refers to forms of tourism which have the following characteristics:

1. All nature-based forms of tourism in which the main motivation of the tourists is the observation and appreciation of nature as well as the traditional cultures prevailing in natural areas.

2. It contains educational and interpretation features.

3. It is generally, but not exclusively organized by specialized tour operators for small groups. Service provider partners at the destinations tend to be small, locally owned businesses.

4. It minimizes negative impacts upon the natural and socio-cultural environment.

5. It supports the maintenance of natural areas which are used as ecotourism attractions by:

- Generating economic benefits for host communities, organizations and authorities managing natural areas with conservation purposes;

- Providing alternative employment and income opportunities for local communities;

- Increasing awareness towards the conservation of natural and cultural assets, both among locals and tourists.

(Source: The British Ecotourism Market, UNWTO 2002)

\section{Impact of Eco-Tourism in Bangladesh:}

The skyrocketing demand for the tourism, especially ecotourism lead different stakeholders to rethink about the ecotourism industry once again. At this time, the thinking is all about sustainable and ecofriendly tourism. Ecotourism has a great impact on different aspects in different dimensions like, economic, social and environmental impacts.

\section{Economic Impacts:}

Tourism especially ecotourism impacts enormously both economic and social aspects particularly in rural habitants and their areas. Ecotourism directly create jobs for the local people and produce array of benefits such as taking care of the tourists, housekeeping. Infrastructure development, poverty reduction, enhancing the standard of living, etc. are some of the indirect impact of developing ecotourism in a particular area. Despite all these benefits, the local people can generate income in different forms of local business.

On the other hand, different indirect jobs are being created through the promotion of ecotourism. Moreover, the establishing of hotel, motel, restaurants is growing and with the rise of these substructures, the demand for quality waiter, cleaner, supplier, sweeper, chef, translator, guide, tour operator also swelling in anincredible way, with the expansion of ecotourism. The transport sector also developed through the ecotourism sector. In a word, it can be said that, the ecotourism sector impacted a lot on the economy of a country. In a statistic by WTTC (2015), it is seen that, tourism contributes nearly BDT $296.6 \mathrm{bn}$. in the GDP in the year 2014 and will contribute BDT 566.3 bn. in the year 2025. Again, for direct employment generation, nearly 1,984,000 
jobs created in the tourism industry and estimated the job will be increased by $2.1 \%$ in the year of 2025 ((WTTC), 2015).

\section{Social Impacts:}

Increasing of ecotourism also makes a change in social status as well as social class. Inception of ecotourism and sports tourism in the recent decades has also enormous social impacts on the society. Entrepreneurs, especially women entrepreneurs in local areas are the prime beneficiaries by the increasing of ecotourism demand. With the expansion of ecotourism, traditional clothing and foods, customized kits and stuffs are becoming popular. The local peoples are getting extra pay with the increasing demand for ecotourism and the tendency of migration becoming lessen, which contributes in the national economy as well.

\section{Environmental Impacts:}

Ecotourism contributes directly on the natural inhabitants. With the expansion of the ecotourism sites, the natural places are preserved, moreover wildlife, local heritage and natural beauty getting preserved. The visitors also fell attraction for this natural sites.

Although there exists many positive impacts for the ecotourism there exists some negative aspects as well for the ecotourism development. In most of the cases, the job creation by the ecotourism is seasonal and in the down season, the people engaged in this sector, look for another job. Again, the attitudes of the tourists sometime hampers the native's cultural emotion and the destruction of the nature by the tourists hampers the natural imbalance.

\section{i. Sundarban:}

\section{Major Ecotourism Destination of Bangladesh:}

The Sundarban is the single largest chunk of productive mangrove forest in the world and one of the most biologically productive of all natural ecosystems (UNESCO, 2017). The Sundarban covers approximately 10,000 square kilometers. Forests, fisheries, wildlife and water comprise the Sundarban's mangrove resources and the mysterious nature of this forest always attracts the nature lover, scientists, researchers and tourists. The core areas of the Sundarban Reserve Forest (SRF) considered as the World Heritage Site. UNESCO declared the Sundarban as a world heritage site in 1997. There are 13 tourist point in Sundarban itself. These are Karamjol, Hiron point, Katka, Nilkomol, Harbaria, Smoronkhola, Tiger Point, Dobeki, Kodomtola, Notabeki, Haldibunia, Dublar Char, Akram Point.

\section{ii. Cox's Bazar:}

Cox's Bazar has been considered as the world's longest sea beach in the world. Approximately, $120 \mathrm{~km}$ (75 mi) unbroken sandy sea beach comprises of a gentle slope. Although it is not a major international tourist destination worldwide, but most visited tourist destinations in Bangladesh today. The Government of Bangladesh formed a special unit of police called 'tourist police' to protect local and foreign visitors, as well as to look after the nature and wildlife in the tourist spots of Cox's Bazar in 2013. Tourist attractions in Cox's Bazar are Himchari National Park, AggmedaKhyang, Ramu, Bangabandhu Sheikh Mujib Safari Park, Inani Beach.

\section{iii. Saint Martin Island:}

The Saint Martin Island is a tiny and isolated island in the northeast part of the Bay of Bengal in Bangladesh. The local name of the island is 'NaricalGingira' meaning 'Coconut Island'. There is also a small adjoining island that is disjointed at high wave, called 'CheraDwip'. In recent decades, Saint Martin Island and Cheradwip has become a popular tourist destination. Different natural resources, the charming attractiveness of Island and the warmth of the local people appeal to the tourist. Stunning landscapes, clear sea water, Coral colony, unique and fresh sea side environment and the roar of beautiful sea waves are the main attraction of thousands of visitors both home and abroad.

\section{iv. KuakataSea Beach:}

Kuakata is a town popular for its stunning sea beach. It is the second largest sea beach in Bangladesh. It is located in the south-eastern part of Bangladesh. Kuakata beach is a sandy area of 18 kilometers long and 3 kilometers wide. Sunrise and sunset seen can be observed without any obstacles over the Bay of Bengal.

\section{v. Madhupur Sal Forest:}

The Sal forests are deliberated as one of the richest ecosystems in respect to forestry diversity in Bangladesh. Madhupur Sal forest is known as 'MadhupurGarh'. It is situated in Madhupurthana under the district of Tangail. Madhupur Sal forest has 45,565.18 acres of land. For the purpose of preserving the 
biodiversity, out of total area, 2525.14 acres of land declared as reserved forest and the remaining 43039.04 acres of land are under the process to be declared as reserved forest. Madhupur Sal Forest contain many sorts of plants, animal and tribal community which is significant for constancy of environment and treasured part of the biological as well as cultural diversity of Bangladesh.

\section{vi. BanghabanduSafari Park:}

Bangabandhu Sheikh Mujib Safari Park is the first Safari Park of its kinds in Bangladesh. This safari park is atoting of an animal reservation situated along the Chittagong-Cox's Bazar road about $50 \mathrm{~km}$ from the Cox's Bazar town. The natural atmospheres of the forest is tropical evergreen and rich with Garjan, Boilam, Telsur and Chapalish woods. This park was customary on the basis of South Asian model. The safari park itself shields a large number of wild elephants which are inherent to the area. Other animal attractions include lions, Crocodiles, Bengal tigers, Bears and lots of different types of birds and monkeys which is magnificent project to appeal to the tourist.

\section{vii. SitakundoEco-Park:}

Sitakundo eco-park is the first eco-park of its kind in Bangladesh with a beautiful botanical garden inside. It was established in 2001 under a five-year (2000-2004) development project on 1,997 acres of land in the Chandranath Hills in Sitakunda, Chittagong. The eco-park was established to facilitate biodiversity conservation, natural rejuvenation, new plantations, infrastructure development, furthermore to encourage nature-based tourism to spawn revenue.

\section{viii. Kaptai:}

The whole kaptai area is a full of natural beauty. The main attractions of Kaptai are the Kaptai National Park, KaptaiLake and the Hanging Bridge over KaptaiLake. Kaptai National Park waterfalls between the Karnaphuly and Kaptai Mountain assortments. Prior to announcement of the national park it was Sitapahar Reserve. In this park, there are lots of old trees which were planted in 1873 and also there are various wildlife such as deer, jungle cat, elephant, monkey, etc. Kaptai National Park is a safe and sanctuary for birds and other wildlife. In Kaptai area, there is a lake called 'Kaptai Lake', which is a man-made lake. The lake was created as a result of building the Kaptai Dam on the KarnaphuliRiver as part of the Karnaphuli Hydro-electric project. There is a hanging bridge over the lake which is also an attractive spots for the tourists.

\section{ix. SajekVally:}

Sajek is comparatively new tourist destination for ecotourism. Basically it is the name of a river which separates Banglades from India. The main attraction of this place is natural beauty and the tribal community. The major ethnic minorities are Chakma, Marma, Tripura, Pankua, Lushai and Sagma. The place is known as 'Hill Queen' for its natural beauty and roof of Rangamati. Sun set, rain, morning, evening, night and spending time with the local natives are some of the most attractive moments in SajekVally.

\section{x. MadhabkundaEco-Park:}

A natural waterfall is the most eye-catching site of this Eco-park. It is situated in Maulvibazar district under Sylhet division. Madhabkunda waterfall is one of the stunning places which have a lot of ecological, regional and economic importance. Madhabkunda is the biggest waterfall in Bangladesh, around $200 \mathrm{ft} .(61 \mathrm{~m})$ high. A special portion of Khasia tribe lives in the forest villagesof this area and involved in some agricultural activities in the forestland. People of this tribal community by tradition grow betel vine, betel nut, cashew nut, pineapple, lemon etc. for their livelihood.

\section{xi. LawacharaNational Park:}

Lawachara is one of the foremost natural reserve in Bangladesh. In 1997 Bangladesh government affirmed it a National Park. This forest is erected by the British, the time of their rule in Indian Subcontinent. Lawachara is the most attractive tropical forests in Bangladesh. It is situated in Maulvibazar district under Sylhet division. The national park is famous for the variety of trees and the wild animals' free movement.

\section{xii. Hakalukihaor:}

Hakalukihaor is one of the Bangladesh's biggest and one of Asia's largest wetland resource. It is the homegrown of numerous animals, fishes and birds and a huge variety of flora and fauna. Fishes of 107 types were available in the haor, some tasty and nutritious fishes like Chela, Dhela, Pabda, Lalchanda fish found here. Rare types of plants, animals, birds can be found here. 


\section{xiii. RatargulSwamp Forest:}

Ratargul Swamp Forest is the only swamp forest of its kinds, located in Bangladesh and one of the few freshwater swamp forests in the world. Locally, the place is also named as the Amazon of Bangladesh. The evergreen forest is located by the river Goain and linked with the cannel ChengirKhal. The forest goes under 2030 feet water in the rainy season and in other time of the year, the water level is around 10 feet deep. It's a decent source of different local fish's inhabitant. It's the territory of different snakes, monkeys, lizards, insects and birds as well.

\section{xiv. Bisnakandi:}

Bisnakandi is one of the newest ecotourism destination in Bangladesh. It is situated at BangladeshIndia border in Sylhet. It is a landscape of beauty among greens and hills. Adding to its charm are dark clouds taking on the mountain in the rainy season and flowing beneath towards BholaganjRiver which is a branch of the Piyain River. It is a natural place that truly attract the tourists especially in rainy season.

\section{Problems for Fostering Ecotourism in Bangladesh:}

Nearly five decades of independence have elapsed, but still now Bangladesh has not rooted its tourism sector than the neighboring countries does. Though there exists a huge potential, especially in ecotourism, Bangladesh has not taken the opportunity. The first comprehensive national tourism policy developed in 2010 and under that policy the tourism authority of Bangladeshhas taken some steps for promoting the tourism sector of Bangladesh as a major tourism destination. Despite huge potentiality, there exists a number of problems. The concerned authority should address the problem and shrink the problems. The most prominent problems are:

- Immature long term vision both government and private sectors as well, to become a prominent ecotourism destination worldwide.

- Negative brand image of Bangladesh as a tourist destination country.

- Lack of product development in tourism potential areas.

- Inefficient promotional activity makes the tourism sector, especially ecotourism sector of Bangladesh, is one of the laggard industry.

- Insufficient infrastructure makes the problem a bit larger.

- Lack of tourism awareness among the domestic people.

- Lack of properly trained manpower in this sector.

- Absence of association of the coordinated agencies.

- Environmental pollution and unplanned development, particularly in tourist resorts.

- Shortage of budgetary allocation also widening the problem. The government should allocate a special fund for the development of the tourism sector.

- Security and safety for the foreign tourists is one of the prime concern for not developing the ecotourism sector of Bangladesh rapidly, etc.

\section{Recommendations}

Bangladesh is a developing country. Ecotourism can be one of the driving force to change the economy of Bangladesh. If the hospitality industry turned it into a professional industry, then the tourism sector as well as the ecotourism will be improved rapidly in Bangladesh. The natural places of Bangladesh can dominate the world's ecotourism destination, but there should have a certain framework through the policy makers. For the development of the ecotourism sector of Bangladesh some recommendations are pointed outbelow:

- The government, with the collaboration of other stakeholders should formulate a long term vision for the development of the ecotourism sector as one of the prominent tourism destination worldwide.

- A comprehensive tourist plan have to be formulated. In most of the cases, the tourists have nothing to do after sunset. So, different stakeholders should have to assess the need of the tourists. And according to the need of tourists, a comprehensive tourist plan should have to be redesigned.

- According to the world tourism demand and supply, the current tourism policy should have to be rectified.

- Different awareness and motivational programs from both government and private sector's end should have to be undertaken for increasing the volume of domestic tourist flow.

- The government may take support from the private sectors for the development of ecotourism spots in different parts of the country.

- Ecotourism places should be given extra broadcasting in different global media/s. So that, the world can know about the places and feel encouraged to spend time in that place, and make the trip as a memorable visit for his/her lifetime.

- Special training program should be arranged for the staffs related to this hospitality industry. 
- Travel mart (fair) should be arranged frequently in different parts of the country.

- Improvement of the infrastructure and establishment of the good connectivity should be ensured.

- Government should also make the Eco tourist places safe for the tourists, especially for the foreign guests. Without ensuring the safety and security, long term return from the ecotourism places cannot be possible.

- Overall neatness and cleanliness of the tourist spots should have to be maintained strictly for attracting the tourists in all the year round.

\section{Conclusions}

Bangladesh is trying to enhance its economy by the best usages of its natural resources. And that's why the government of Bangladesh declares tourism sector as one of the thrust sectors, moreover declared 2016 as tourism year. Bangladesh is a country full of natural resources, indigenous culture, geographic location and untouched reserves of a variety of unique and magnificent creatures. With all the forests, beaches, lakes, rivers and hills makes the ideal place for ecotourism development. For Bangladesh, although, this is relatively new sector, but there exists huge potentiality if extensive care taken and promote the ecotourism attractive places properly in the world. Bangladesh has the world's biggest mangrove forest ecosystem, world's longest sea beach, incredible hilly districts (Bandarban, Khagrachari, Rangamati), a vast marine world, and the largest manmade lake, which can be easily promoted to the Eco tourists. Obviously, these places indicates the huge potentiality of Bangladeshi ecotourism prospects. But there exists some problems. The government along with the private sector should come forward and develop a comprehensive master plan for the development of ecotourism sites as world class tourism destinations. The tourist places like Ratargul (Sylhet), Saint-Martin Island, Kuakatabeach are some of the important tourist areas that should bedeveloped by doing a master plan for attracting both foreign and domestic tourists in all the year round. The government should provide a positive look at developing the human resource infrastructure required for developing tourism sector in the country. Highly professional and technical human resource competent in tourism can contribute positively to satisfying diversified needs of different tourists. A specialized institution for tourism education may be established in this regard to foster the tourism sector of Bangladesh. The initiatives to establish regional inter-country taskforce initiated by the present Government of Bangladesh to combat the possible terrorist attacks and activities may contribute positively in the tourism sector. Besides the above mentioned supports and services the entrepreneurs in the field of tourism industry should be supported and encouraged by establishing government grants and subsidies and adopting country's tourism policy that may be used as the guideline for the rapid expansion of this sector.

\section{Reference}

[1]. Cater, E. (1995). Environmental Contradictions in Sustainable Tourism. The Geographical Journal, 161(1), 21-28. doi: $10.2307 / 3059924$

[2]. Das, S. (2011). Ecotourism, Sustainable Development and the Indian State. Economic and Political Weekly, 46(37), 60-67.

[3]. Das,D.,and Hossain,I.,(2016)Does ecotourism affect economic welfare? Evidence from Kaziranga National Park, India,Journal of Ecotourism, 15(3),241-260.

[4]. Goodwin, H. (1996). In pursuit of ecotourism. Biodiversity \& Conservation, 5(3), 277-291.

[5]. Jamrozy, U. (2007). Marketing of tourism: a paradigm shift toward sustainability. International Journal of Culture, Tourism and Hospitality Research, 1(2), 117-130. doi: doi:10.1108/17506180710751669

[6]. Li, W., \& Han, N. (2001). Ecotourism Management in China's Nature Reserves. Ambio, 30(1), 62-63.

[7]. Okaka, W. (2007). The role of media communications in developing tourism policy and cross cultural communication for peace, security for sustainable tourism industry in Africa. Paper presented at the Proceedings of the 4 th International Institute of Peace through Tourism (IIPT), African Conference on Peace through Tourism at Educators' Forum, Kampala (Uganda).

[8]. Rasul, G., \& Manandhar, P. (2009). Prospects and Problems in Promoting Tourism in South Asia A Regional Perspective. South Asia Economic Journal, 10(1), 187-207.

[9]. Russell, A., \& Wallace, G. (2004). Irresponsible Ecotourism. Anthropology Today, 20(3), 1-2.

[10]. Salam, M. A., Lindsay, G. R., \& Beveridge, M. C. M. (2000). Eco-tourism to Protect the Reserve Mangrove Forest the Sundarbans and its Flora and Fauna. Anatolia, 11(1), 56-66. doi: 10.1080/13032917.2000.9686983

[11]. Shamsuddoha, M., \& Nasir, T. (2011). Eco-tourism: A descriptive study on Sitakunda Ecopark in Chittagong division of Bangladesh. International J. Educational Res. and Tech, 2(1), 8-13.

[12]. Shoeb-Ur-Rahman, M., \& Shahid, R. B. (2012). A growing dilemma of tourism diffusion and sustainability: wows and woes for Bangladesh eco-tourism! UTMS Journal of Economics, 3(1), 57.

[13]. The World Travel \& Tourism Council (WTTC), (2015). Travel \& Tourism Economic Impact 2015, Bangladesh.

[14]. Ugurlu, T. (2010). Definintion of Tourism (UNWTO Definition of Tourism)/ What Is Tourism?Retrieved 16 February, 2017, from http://www.tugberkugurlu.com/archive/definintion-of-tourism-unwto-definition-of-tourism-what-is-tourism

[15]. UNESCO. (2017). Sundarbans National Park. Retrieved 02 March, 2017, from http://whc.unesco.org/en/list/452

[16]. UNWTO. Why tourism? Retrieved 16 February, 2017, from http://www2.unwto.org/content/why-tourism

[17]. UNWTO. (2016). UNWTO Tourism Highlights, (2016 Edition): The World Tourism Organization.

[18]. Wikipedia. (2017a). Ecotourism. Retrieved 18 February, 2017, from https://en.wikipedia.org/wiki/Ecotourism

[19]. Wikipedia. (2017b). Tourism in Bangladesh. https://en.wikipedia.org/wiki/Tourism_in_Bangladesh 